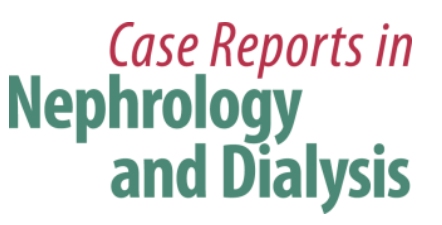

Case Rep Nephrol Dial 2016;6:26-31

DOI: $10.1159 / 000444251$

Publisnea onine: Virarch 2, 2016

(C) 2016 The Author(s)

Published by S. Karger AG, Basel

2296-9705/16/0061-0026\$39.50/0

www.karger.com/cnd

This article is licensed under the Creative Commons Attribution-NonCommercial 4.0 International License (CC BY-NC) (http://www.karger.com/Services/OpenAccessLicense). Usage and distribution for commercial purposes requires written permission.

\title{
Treatment of Kidney Stone in a Kidney-Transplanted Patient with Mini-Percutaneous Laser Lithotripsy: A Case Report
}

\author{
Dean Markića $^{\mathrm{a}}$ Kristian Krpina $^{\mathrm{a}}$ Juraj Ahel ${ }^{\mathrm{a}} \quad$ Antun Grškovića $^{\mathrm{a}}$ \\ Josip Španjol ${ }^{a} \quad$ Nino Rubinića $\quad$ Mauro Materljan $^{a} \quad$ Ivana Mikolašević $^{b}$ \\ Lidija Orlićb $^{b}$ Sanjin Rački ${ }^{b}$ \\ Departments of ${ }^{a}$ Urology and ${ }^{b}$ Nephrology and Dialysis, University Hospital Rijeka, \\ Rijeka, Croatia
}

\section{Key Words}

Mini-percutaneous nephrolithotripsy $\cdot$ Renal transplantation $\cdot$ Living donor $\cdot$ Nephrolithiasis

\begin{abstract}
We report a case of a kidney-transplanted patient with urolithiasis treated with minipercutaneous laser lithotripsy. The patient presented with renal dysfunction and graft hydronephrosis. Diagnostic procedures revealed ureterolithiasis as a cause of obstruction, and percutaneous nephrostomy was inserted as a temporary solution. Before surgery, the stone migrated to the renal pelvis. Mini-percutaneous laser lithotripsy was successfully performed, and during surgery, all stone fragments were removed. Six months after successful treatment, the patient has good functioning and stone-free graft.

(C) 2016 The Author(s)

Published by S. Karger AG, Basel
\end{abstract}

\section{Introduction}

Kidney transplantation is the treatment of choice for patients with end-stage renal disease because it offers prolonged survival and better quality of life [1]. Nephrolithiasis in a transplanted kidney is an uncommon complication, with an incidence reported from 0.2 to $1.7 \%$ [2]. The most frequent causes of stone formation after kidney transplantation are hyperparathyroidism, ureteral obstruction, chronic urinary stasis, foreign body (specially nonabsorbable suture material), vesicoureteral reflux, metabolic diseases (gout, hyperoxalu-

\section{KARGER}

Dean Markić

Department of Urology, University Hospital Rijeka

Tome Strižića 3

HR-51000 Rijeka (Croatia)

E-Mail dean.markic@ ri.htnet.hr 


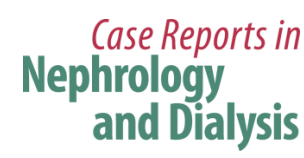

Case Rep Nephrol Dial 2016;6:26-31

DOI: $10.1159 / 00044425$

(C) 2016 The Author(s). Published by S. Karger AG, Base www.karger.com/cnd

Markić et al: Treatment of Kidney Stone in a Kidney-Transplanted Patient with MiniPercutaneous Laser Lithotripsy: A Case Report

ria) and preexisting stone in a donor kidney [3]. Immunosuppressive medications, particularly cyclosporine, increase urine concentration and serum and urine uric acid levels, which may promote stone formation. Stones are more frequently found in female patients. Kidney stones are more common than ureteral stones. The treatment of these patients is challenging due to immunosuppressive drugs used, usually altered renal function, altered renal innervation that masks the typical presenting symptoms, and disturbed anatomy (specially ureterovesical junction).

Management of urolithiasis in transplanted patients is similar to that in the general population and includes active surveillance, extracorporeal shock-wave lithotripsy (ESWL), percutaneous nephrolithotripsy (PCNL), ureteroscopy and open surgery [4, 5]. In this report, we describe a patient with kidney transplantation and nephrolithiasis treated with PCNL using smaller instruments (mini-PCNL).

\section{Case Report}

A 30-year-old man with a transplanted kidney and urolithiasis was admitted to our hospital for mini-PCNL. Nineteen years ago, the patient had received a kidney transplant from a living donor (mother). The cause of end-stage renal disease was obstructive uropathy caused by posterior urethral valves. He has had multiple operations in his childhood including bladder augmentation with large bowel. The kidney was transplanted in the right iliac fossa, and the ureter was anastomosed on the augmented part of the bladder. After transplantation, immunosuppression was started with cyclosporine, azathioprine and prednisolone. The further postoperative clinical course was eventless, and the function of the transplanted kidney was excellent during follow-up.

Three weeks before admission, he became febrile and oliguric. Ultrasonography revealed graft hydronephrosis, and laboratory exams showed elevated renal function with urea $11.0 \mathrm{mmol} / \mathrm{l}$ and creatinine $447 \mu \mathrm{mol} / \mathrm{l}$. X-ray showed a suspected stone in the pelvis, and percutaneous nephrostomy was inserted. Antegrade pyelography confirmed the stone in the proximal ureter. Proteus mirabilis was isolated from the urine culture, and targeted therapy (ceftriaxon) was implemented. After 2 days, the patient became afebrile, and his laboratory exams became normal. On control X-ray, migration of the stone from the proximal ureter to the renal pelvis was noticed (fig. 1). The patient was prepared for mini-PCNL.

The mini-PCNL treatment was carried out in the supine position and general anesthesia. We used the previously performed percutaneous nephrostomy as a guide for dilation. The hydrophilic guide wire with floppy tip was inserted into the pelvicalyceal system through the nephrostomy. After putting the guide wire through the nephrostomy, the nephrostomy was removed. The skin incision was made along the guide wire, and dilatation was performed using a single metal dilator using the one-step bougie technique. Via this dilator, the suitable 15/16-Ch operating sheath (Karl Storz, Tuttlingen, Germany) was placed in the renal pelvicalyceal system. Dilation and advancement of the operating sheath was accomplished under X-ray control. A mini-nephroscope (instrument sheath diameter $12 \mathrm{Ch}$ with 6.7 Ch working channel; Karl Storz) was introduced through the operating sheath. The stone was visualized in the renal pelvis (fig. 2). Holmium:YAG laser lithotripsy using $365 \mu \mathrm{m}$ laser fibers was performed (Calculase II SCB, Karl Storz) using an appropriate energy level. Stone fragments were removed with graspers. Also, the hydrodynamic effect of the specially designed sheath allowed evacuations of fragmented stones between the sheath and nephroscope and without additional intrarenal pressure elevation. Antegrade placement of a ureteral stent was unsuccessful, and a temporary percutaneous nephrostomy was positioned in 


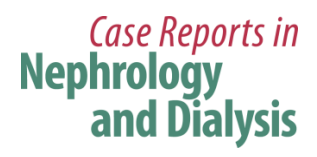

Case Rep Nephrol Dial 2016;6:26-31

DOI: $10.1159 / 00044425$

(C) 2016 The Author(s). Published by S. Karger AG, Basel www.karger.com/cnd

Markić et al.: Treatment of Kidney Stone in a Kidney-Transplanted Patient with MiniPercutaneous Laser Lithotripsy: A Case Report

the renal pelvis (fig. 3). The postoperative course was uneventful. The stone analyses showed that it was mixed from calcium oxalate and calcium phosphate. Six months after mini-PCNL, kidney function parameters were normal, and the graft is stone free.

\section{Discussion}

Renal colic is typically a symptom of urolithiasis. Since allografted kidney and ureter are denervated, transplanted patients do not have pain. The stone is usually found during routine ultrasonography or in diagnostic procedures of other complications such as fever, infection, hematuria and renal dysfunction [4]. In our patient, renal dysfunction led the clinician to perform ultrasonography, which revealed graft hydronephrosis. Another more sophisticated and accurate method for the detection of stone is computerized tomography.

In case of renal obstruction, as in our patient, resolving the obstruction is the primary aim. After revealing the obstruction, definitive stone management must be performed. Resolving the stone with open surgery is the traditional method. However, open surgical procedure has a many disadvantages: preparation of kidney and ureter is very difficult due to their adherence to adjacent tissue, potentially postoperative complications such as infection may occur, urinary fistula are difficult to overcome, the postoperative pain is increased and the patient's recovery is slow. To overcome these negative sides of open surgery, minimally invasive methods have become the standard of care in most patients with urolithiasis both in general patients and transplanted patients [4]. Also, laparoscopy can be used in the management of complex stone cases.

ESWL is a valuable, noninvasive method for stone management, but some limitations exist in transplanted patients. Difficult localization of the stone due to overlying bony pelvis may represent a limiting factor for ESWL, and the shock wave can be blocked by pelvic bones. Also, after treatment, the stone fragment must pass through ureterovesical junction, which can be demanding. About $60 \%$ of patients treated with ESWL needed multiple sessions. Usually, ESWL is a reasonable treatment for calculi smaller than $1.5 \mathrm{~cm}$.

Another possibility is ureteroscopy, but this is a technically challenging intervention in kidney transplants, because of the mostly difficult cannulation of the ureterovesical anastomosis. Ureterovesical anastomosis is usually located at the bladder apex, making ureteral intubation and entry in the ureter very difficult. For example, in one study, successful intubation was performed in only $37.5 \%$ patients [6]. Flexible ureteroscopy is recommended for adequate access and desintegration of calculi and can be done by electrohydraulic lithotripsy, ultrasonic lithotripsy or holmium laser in the ureter and kidney, with a success rate of 67-100\% [4].

PCNL, in the general population, is recommended as the therapy of choice for large renal calculi $(<20 \mathrm{~mm})$ and also for smaller stones $(10-20 \mathrm{~mm})$ unsuitable for ESWL. Stone-free rates following PCNL have been reported, which range from 76-98\% [7]. However, PCNL is still a challenging procedure and can be associated with significant complications. To decrease morbidity associated with larger instruments like blood loss, postoperative pain and potential renal damage, a modification of the technique of standard PCNL has been developed. This is performed with a miniature endoscope via a small percutaneous tract (11-20 $\mathrm{Ch}$ ) and was named minimally invasive PCNL or mini-PCNL. Usually, the term mini-PCNL is used for operative sheaths below $20 \mathrm{Ch}$. The benefits of mini-PCNL are lower blood loss, increased intrarenal maneuverability, decreased postoperative pain and limited hospital stay. Limitations are the necessity to disintegrate stones into small enough fragments to fit through a reduced-size sheath, which results in longer operative times [7]. 


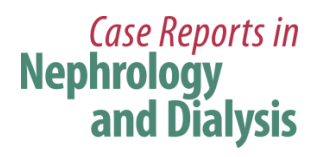

\begin{tabular}{l|l}
\hline Case Rep Nephrol Dial 2016;6:26-31 \\
\hline DOI: 10.1159/000444251 & $\begin{array}{l}\text { ○ 2016 The Author(s). Published by S. Karger AG, Basel } \\
\text { www.karger.com/cnd }\end{array}$ \\
\hline
\end{tabular}

Markić et al.: Treatment of Kidney Stone in a Kidney-Transplanted Patient with MiniPercutaneous Laser Lithotripsy: A Case Report

The first renal stone extraction through percutaneous access in a renal transplant patient was performed in 1982 [8]. Because of the relative superficial position of transplanted kidneys, percutaneous management is favored [9]. This is specially recommended in stones larger than $1.5 \mathrm{~cm}$. Percutaneous removal of stones in a transplanted kidney has the best success rate, but it is an invasive procedure on a single functioning kidney.

Ji et al. [10] presented their experience with mini-percutaneous laser lithotripsy. They treated 11 patients with kidney allograft lithiasis using mini-PCNL. The stones ranged from $0.9-2.4 \mathrm{~cm}$ in diameter. The stones were successfully disintegrated using laser in all patients.

Compared to PCNL in the general population, the ultrasound-guided puncture of a transplanted kidney in the iliac fossa is a relatively simple procedure because the graft is situated just below the muscles of the anterior abdominal wall. Also, the distance from skin to kidney is small, and the dilation is also easier than in the general population. The important issue for transplanted patients is the extent of kidney damage because standard operative sheaths are 26-32 Ch in diameter compared to $15 / 16 \mathrm{Ch}$ in mini-PCNL. It is obvious that mini-PCNL is a less invasive method with good efficacy for stone management. According to our limited experience and data from the literature, we believe that mini-PCNL can become a procedure of choice in transplanted patients with obstructive stones in the kidney and upper ureter.

\section{Statement of Ethics}

Subjects have given their informed consent.

\section{Disclosure Statement}

The authors of this case report have no conflicts of interest to disclose.

\section{References}

$>1$ Wolfe RA, Ashby VB, Milford EL, Ojo AO, Ettenger RE, Agodoa LY, Held PJ, Port FK: Comparison of mortality in all patients on dialysis, patients on dialysis awaiting transplantation, and recipients of a first cadaveric transplant. N Engl J Med 1999;341:1725-1730.

- Klingler HC, Kramer G, Lodde M, Marberger M: Urolithiasis in allograft kidneys. Urology 2002;5:344-348.

-3 Van Gansebeke D, Zalcman M, Matos C, Simon J, Kinnaert P, Struyven J: Lithiasis complications of renal transplantation: the donor graft lithiasis concept. Urol Radiol 1985;7:157-160.

4 Challacombe B, Dasgupta P, Tiptaft R, Glass J, Koffman G, Goldsmith D, Khan MS: Multimodal management of urolithiasis in renal transplantation. BJU Int 2005;96:385-389.

-5 Markić D, Valenčić M, Gršković A, Španjol J, Sotošek S, Fučkar Ž, Maričić A, Pavlović I, Budiselić B: Extracorporeal shockwave lithotripsy of ureteral stone in a patient with en bloc kidney transplantation: a case report. Transplant Proc 2011;43:2110-2112.

6 He ZH, Zeng GH, Yuan J, et al. Endoscopic techniques on treatment of upper urinary tract calculi in transplanted kidneys. J Clin Rehabil Tiss Eng Res 2011;15:9925-9927.

7 Ferakis N, Stavropoulos M: Mini percutaneous nephrolithotomy in the treatment of renal and upper ureteral stones: lessons learned from a review of the literature. Urol Ann 2015;7:141-148.

-8 Fisher MF, Haaga JR, Persky L, Eckel RE, Puma JL: Renal stone extraction through a percutaneous nephrostomy in a renal transplant patient. Radiology 1982;144:95-96.

-9 Rifaioglu MM, Berger AD, Pengune W, Stoller ML: Percutaneous management of stones in transplanted kidneys. Urology 2008;72:508-512.

10 Ji ZG, Tian Y, Chen Q, Liu Z, Lin J, Wang JM, Ma LL, Guo HB, Tang YW, Xie ZL, Sun W, Zhang L: A retrospective study of minipercutaneous laser lithotripsy for treatment of allograft kidney lithiasis obstruction. Transplant Proc 2013;45:3298-3301. 
Case Reports in

Nephrology

and Dialysis
Case Rep Nephrol Dial 2016;6:26-31

\begin{tabular}{l|l}
\hline DOI: $10.1159 / 000444251$ & C 2016 The Author(s). Published by S. Karger AG, Basel
\end{tabular} www.karger.com/cnd

Markić et al.: Treatment of Kidney Stone in a Kidney-Transplanted Patient with MiniPercutaneous Laser Lithotripsy: A Case Report

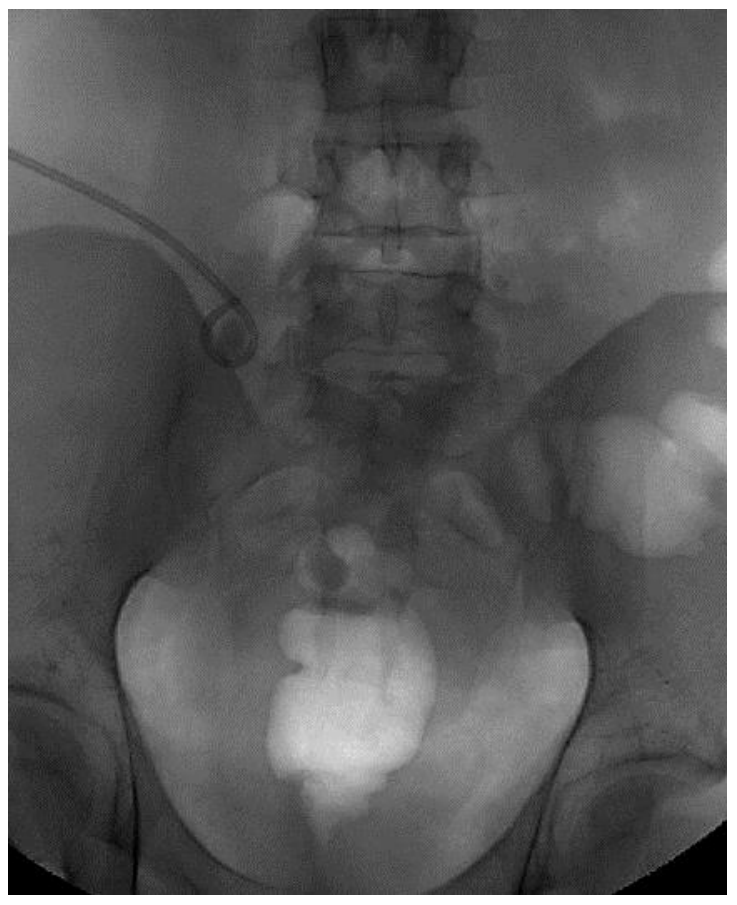

Fig. 1. Pretreatment X-ray showed ureteral stone in the renal pelvis close to the loop of nephrostomy.

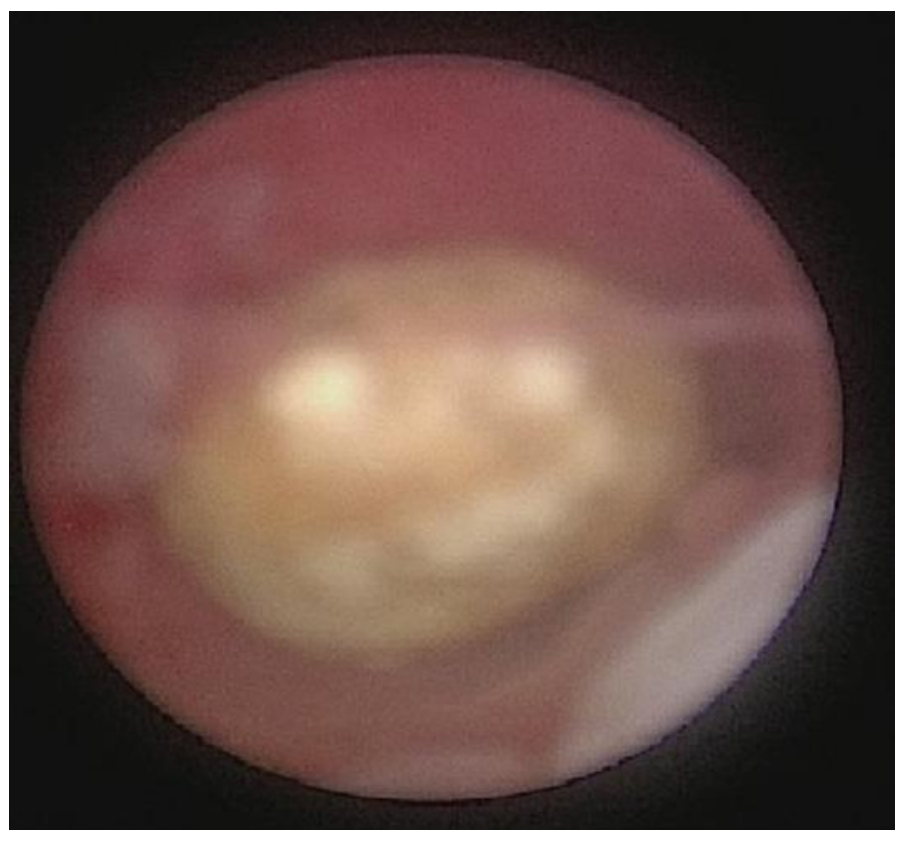

Fig. 2. Nephroscopic view of renal pelvis stone before starting the lithotripsy. 
Case Reports in

Nephrology

and Dialysis
Case Rep Nephrol Dial 2016;6:26-31

\begin{tabular}{l|l}
\hline DOI: $10.1159 / 000444251$ & (C) 2016 The Author(s). Published by S. Karger AG, Basel
\end{tabular} www.karger.com/cnd

Markić et al.: Treatment of Kidney Stone in a Kidney-Transplanted Patient with MiniPercutaneous Laser Lithotripsy: A Case Report

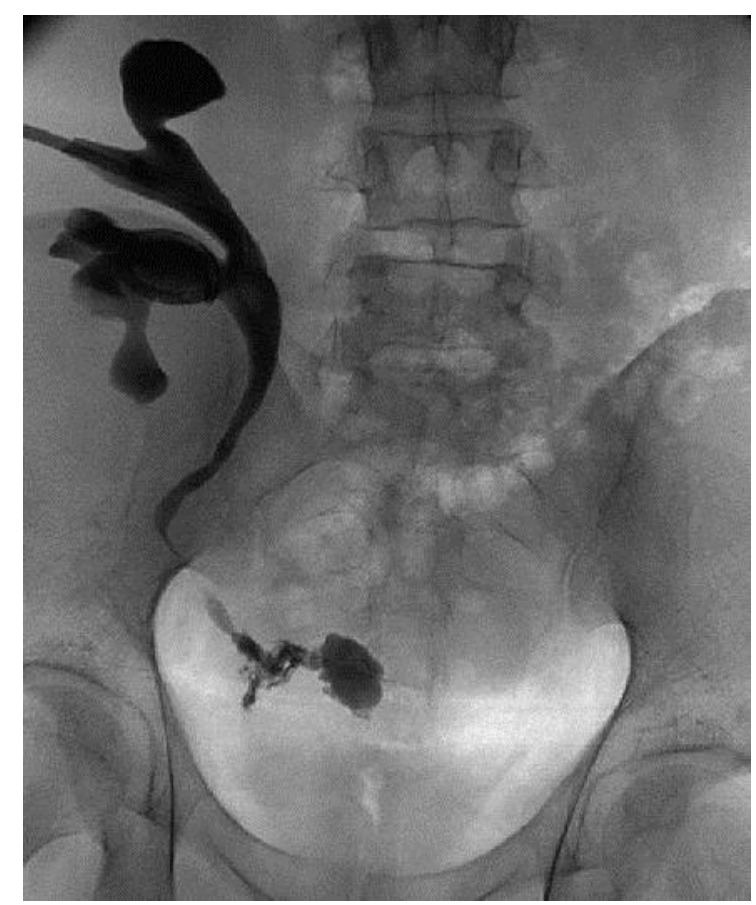

Fig. 3. Postoperative X-ray revealed stone-free graft with contrast eliminated to the bladder. 